\title{
Synthesis and Properties of Polyurethane Elastomers Containing Sucrose as a Cross-Linker
}

\author{
Kazunori Kizuka*, Shin-Ichi Inoue \\ Applied Chemistry Department, Aichi Institute of Technology, Toyota, Japan \\ Email: ${ }^{*}$ 13801ww@aitech.ac.jp
}

Received 24 September 2015; accepted 27 October 2015; published 30 October 2015

Copyright (C) 2015 by authors and Scientific Research Publishing Inc.

This work is licensed under the Creative Commons Attribution International License (CC BY). http://creativecommons.org/licenses/by/4.0/

(c) $\underset{\mathrm{EY}}{\mathrm{B}}$ Open Access

\begin{abstract}
Polyaddition using isocyanate and polyol forms polyurethane elastomer (PUE). However, this method has rarely been applied to the construction of PUEs containing sucrose. Hence, the introduction of sucrose (disaccharide) as a cross-linker via polyaddition remains a challenging subject in polymer chemistry. Here, we report the synthesis of PUEs using an aromatic isocyanate $\left(4, \mathbf{4}^{\prime}\right.$-diphenylmethane diisocyanate), polyols including a polyether polyol (polytetramethylene glycol) and two polyester polyols (polycaprolactone and polycarbonate diols), and sucrose as a crosslinker by a one-shot method. The PUEs containing sucrose were successfully produced. The use of sucrose was essential to obtain the desired PUEs containing sucrose units in the main chain.
\end{abstract}

\section{Keywords}

Polyaddition Reaction, Polyurethane Elastomer, Sucrose, Cross-Linker

\section{Introduction}

A variety of organic polymer materials are utilized in our daily lives, and those derived from sugar have been actively investigated in recent years. Polymer materials (e.g., polyurethanes) containing sugar are expected to replace materials derived from petroleum and to be used as bio-based materials. Polyurethanes [1] are used in a surprising array of commercial applications, which, for convenience, are classified into seven major product types [2]-[7]: flexible slab, flexible molded foam, rigid foam, solid elastomers, reaction injection molded materials, carpet backing, and one- and two-component formulations for coatings, adhesives, and sealants. Building

\footnotetext{
"Corresponding author.
}

How to cite this paper: Kizuka, K. and Inoue, S.-I. (2015) Synthesis and Properties of Polyurethane Elastomers Containing Sucrose as a Cross-Linker. Open Journal of Organic Polymer Materials, 5, 103-112. 
on such a background, we are interested in solid elastomers that are widely used for commercial products, and hence we attempted to develop polymer materials with new functionalities. Various studies have used natural products as raw materials [8]-[20], initiators [21]-[23], and coating agents [24]-[26]. In addition, polyurethane elastomers (PUEs) containing natural products have been used as biocompatible materials in the medical field [27] [28]. We focused on the synthesis of PUEs containing natural products. The use of sugar as a natural product was essential to obtain the desired PUEs containing sugar units in the main chain. PUEs containing sugar may be used for many purposes such as heat insulation, tremor insulation, and as cases for commercial instruments. Typically, sugar is reduced in organic solutions, producing aldehyde and ketone groups. Thus, non-reducing sugar, which retains hydroxyl groups in solution, was ideal to introduce sugar units into the main chain. We selected sucrose as a representative non-reducing sugar. Sucrose has three primary hydroxyl groups and five secondary hydroxyl groups. Sucrose can be derived from sugarcane, sugar beet, and corn. Sucrose is composed of a fructose and a glucose ring linked by a glycosidic bond. Sucrose is one of the world's most abundant organic chemicals, and it is available in a high-purity state at low cost.

Here, we report a synthesis of novel PUEs containing sucrose using the aromatic isocyanate (4,4'-diphenylmethane diisocyanate (MDI)), different types of polyols (polyether polyol: polytetramethylene glycol and polyester polyols: polycaprolactone and polycarbonate diols), and sucrose by a one-shot method [29] to form the corresponding PUEs containing sucrose units in the main chain.

\section{Experimental}

\subsection{Materials}

MDI (MILLIONATE MT) and polycarbonate diol (molecular weight = 2000; PCD2000) (NIPPOLLAN 980N) were supplied from Tosoh Industry, Tokyo, Japan. Polytetramethylene glycol (molecular weight = 2000; PTMG2000) (TERATHANE 2000) was supplied from Invista Industry, Texas, USA. Polycaprolactone diol (molecular weight = 2000; PCL2000) (PLACCEL 2000) was supplied from Daicel Industry, Osaka, Japan. MDI was purified by distillation under reduced pressure $(267-400 \mathrm{~Pa})$ at $100^{\circ} \mathrm{C}$ before use. Sucrose was purchased from NacalaiTesque, Kyoto, Japan and used without further purification. Tetrahydrofuran (THF) and benzene were purchased from NacalaiTesque and distilled over calcium hydride under an Ar atmosphere. $N, N$-dimethylformamide (DMF) and dimethyl sulfoxide (DMSO) were purchased from NacalaiTesque and stored over 4 $\AA$ molecular sieves before use. The following compounds were purchased from commercial suppliers and used as received: dimethyl sulfoxide-d6 (DMSO-d6) (Euriso Top, Saint-Aubin, France), hexane (NacalaiTesque), and acetone (NacalaiTesque).

\subsection{Synthesis of Polyurethane Elastomers Containing Sucrose}

The PUEs containing sucrose units were prepared from MDI, one of the three polyols (PTMG2000, PCL2000, or PCD2000), and sucrose as a cross-linker by a one-shot method (Scheme 1). The recipe and sucrose content for each PUE are listed in Table 1. NCO/OH molar ratio is 2 for all the PUEs containing sucrose. The yields of the sucrose-containing PUEs were quantitative within 10 - 25 min, and the actual sucrose contents in each synthesized PUE agreed with the theoretically expected values. Interestingly, the reaction solutions showed different inherent viscosities, and the viscosity of the polymers increased with the sucrose contents. In addition, the sucrose-containing PUEs below $10 \mathrm{wt} \%$ were transparent. The thin PU sheets $(\sim 0.5 \mathrm{~mm})$ were obtained by casting the resulting PUE solution (20 g). For the sucrose-containing PUEs prepared using PTMG2000, the formations of sheets were achieved using a disposable container at room temperature $\left(23^{\circ} \mathrm{C} \pm 2^{\circ} \mathrm{C}\right)$ for $15 \mathrm{~h}$. For the sucrose-containing PUEs using PCL2000 and PCD2000, the sheets were formed using a disposable container at $100^{\circ} \mathrm{C}$ for $15 \mathrm{~h}$. All the obtained sheets were then cured at $80^{\circ} \mathrm{C}$ for $6 \mathrm{~h}$ in vacuo.

For example, the synthesis of PUE-PTMG-S1 was performed as follows. A solution of sucrose $(0.34 \mathrm{~g}, 0.10 \times$ $\left.10^{-3} \mathrm{~mol}\right)$ and DMF $(10 \mathrm{~mL})$ was prepared and heated at $100^{\circ} \mathrm{C}$ for $15 \mathrm{~min}$ under an Ar atmosphere. MDI (5.0 g, $\left.2.0 \times 10^{-2} \mathrm{~mol}\right)$, PTMG2000 (18 g, $\left.0.90 \times 10^{-2} \mathrm{~mol}\right)$, THF $(20 \mathrm{~mL})$, and the sucrose/DMF solution were then added to a $100-\mathrm{mL}$ four-necked separable reaction flask equipped with a mechanical stirrer, a gas inlet tube, and a reflux condenser. This mixture was stirred at $80^{\circ} \mathrm{C}$ for 20 min under an Ar atmosphere. The thin polymer sheets $(\sim 0.5 \mathrm{~mm})$ were obtained by casting the resulting solution $(20 \mathrm{~g})$ using a disposable container at room temperature $\left(23^{\circ} \mathrm{C} \pm 2^{\circ} \mathrm{C}\right)$ for $15 \mathrm{~h}$. The obtained sheet was cured at $80^{\circ} \mathrm{C}$ for $6 \mathrm{~h}$ in vacuo. 

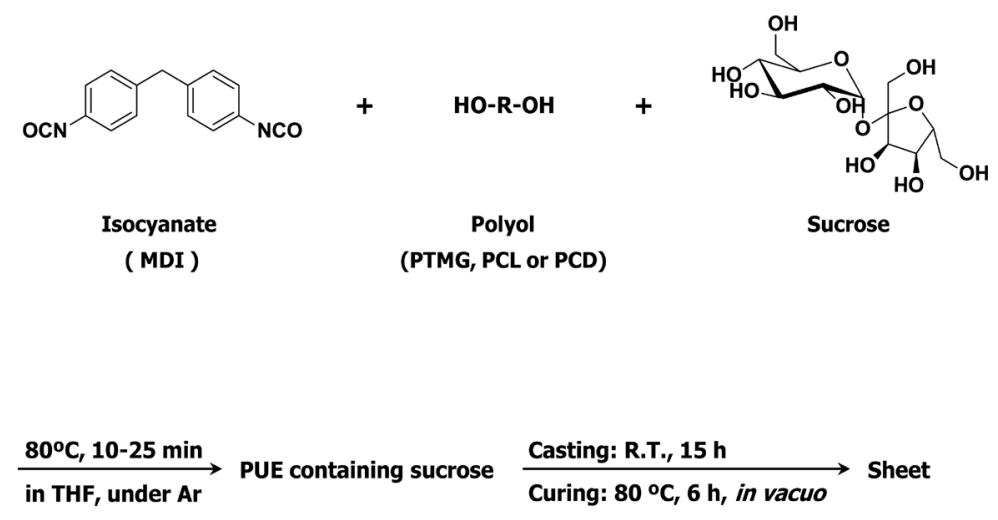

Scheme 1. Synthesis of polyurethane elastomers containing sucrose by a oneshot method.

Table 1. Synthesis of polyurethane elastomers containing sucrose.

\begin{tabular}{ccccc}
\hline Sample & $\begin{array}{c}\text { MDI } \\
\left(\mathrm{mol} \times 10^{-2}\right)\end{array}$ & $\begin{array}{c}\text { Polyol }^{\mathrm{a}} \\
\left(\mathrm{mol} \times 10^{-2}\right)\end{array}$ & $\begin{array}{c}\text { Sucrose } \\
\left(\mathrm{mol} \times 10^{-3}\right)\end{array}$ & $\begin{array}{c}\text { Sucrose content } \\
(\mathrm{wt} \%)\end{array}$ \\
\hline PUE-Polyol-S1 & 2.0 & 0.90 & 0.10 & 1.4 \\
PUE-Polyol-S2 & 2.0 & 0.80 & 0.20 & 3.1 \\
PUE-Polyol-S3 & 2.0 & 0.70 & 0.30 & 5.0 \\
PUE-Polyol-S4 & 2.0 & 0.60 & 0.40 & 7.6 \\
PUE-Polyol-S5 & 2.0 & 0.50 & 0.50 & 10 \\
PUE-Polyol & 2.0 & 1.0 & - & - \\
\hline
\end{tabular}

${ }^{a}$ Polyols: polyoxytetramethylene glycol (molecular weight = 2000; PTMG2000), polycaprolactone diol (molecular weight = 2000; PCL2000), and polycarbonate diol (molecular weight $=2000$; PCD2000).

\subsection{Characterization}

All analyses and tests were performed at room temperature $\left(23^{\circ} \mathrm{C} \pm 2^{\circ} \mathrm{C}\right)$ unless otherwise indicated.

\subsubsection{Nuclear Magnetic Resonance (NMR) Spectroscopy}

${ }^{1} \mathrm{H}$ NMR (300 MHz) and ${ }^{13} \mathrm{C}$ NMR (75.4 MHz) analyses were performed on a Varian Unity Plus-300 spectrometer in DMSO- $d 6$ using tetramethylsilane as the internal standard.

\subsubsection{Fourier Transform Infrared (FTIR) Spectroscopy}

FTIR spectroscopy was performed on a JASCO FTIR-5300 using the attenuated total reflectance (ATR) and transmission methods. The ATR spectra were obtained using an ATR500/M with an ATR prism KRS-5.

\subsubsection{Gel Permeation Chromatography (GPC)}

The average molecular weight and molecular distributions were measured using a Tosoh (Tokyo, Japan) Gel Permeation Chromatograph (GPC) equipped with SD-8022, CCPD, CO-8020 and RI-8020. The measurement conditions for GPC were as follows: sample, $0.1 \mathrm{wt} \%$ (DMF/DMSO = 1/1 solution); solvent, DMF; column, TSK gels $\alpha$-M and TSK GUARDCOLUMN $\alpha$; flow rate, $500 \mu \mathrm{L} / \mathrm{min}$ at $40^{\circ} \mathrm{C}$; quantum, polystyrene transformation method.

\subsubsection{Chemical Properties}

Solubility tests were performed using $15 \times 15 \mathrm{~mm}$ test pieces. Each test piece was soaked in a solvent (benzene, hexane, acetone, THF, DMF, or DMSO; $8.0 \mathrm{~mL}$ ) at room temperature $\left(23^{\circ} \mathrm{C} \pm 2^{\circ} \mathrm{C}\right.$ ) or $100^{\circ} \mathrm{C}$ (for DMF and DMSO) for $24 \mathrm{~h}$.

Swelling tests were performed using $15 \times 15 \mathrm{~mm}$ test pieces. The degree of swelling (Rs) was calculated us- 
ing the formula Rs $(\%)=\mathrm{W}^{\prime} / \mathrm{W} \times 100$, where $\mathrm{W}^{\prime}$ is the weight of the test piece soaked in benzene for $24 \mathrm{~h}$, and $\mathrm{W}$ is the weight of the test piece after drying at $30^{\circ} \mathrm{C}$ for $24 \mathrm{~h}$ in vacuo.

\subsubsection{Mechanical Properties}

Hardness tests were performed using a Kobunshi Keiki ASKER DUROMETER (JIS A type) with test pieces stacked to achieve a thickness of $6 \mathrm{~mm}$.

Tensile tests were performed on an Orientec RTC-1225A with a model-U-4300 using a JIS 3-dumbell as the standard sample and a crosshead speed of $100 \mathrm{~mm} / \mathrm{min}$.

\subsubsection{Thermal Properties}

Dynamic mechanical analyses (DMA) were performed on a Seiko Instruments DMS 6100 at a heating rate of $5^{\circ} \mathrm{C} /$ min over from $-100^{\circ} \mathrm{C}$ to $300^{\circ} \mathrm{C}$ and at $20 \mathrm{~Hz}$ under an $\mathrm{N}_{2}$ atmosphere.

Differential scanning calorimetry (DSC) measurements were performed on a Rigaku Thermo-Plus DSC-8230 at a heating rate of $10^{\circ} \mathrm{C} / \mathrm{min}$ from $-120^{\circ} \mathrm{C}$ to $200^{\circ} \mathrm{C}$ under an $\mathrm{Ar}$ atmosphere. Approximately $9.5 \mathrm{mg}$ of each PUE was weighed and sealed in an aluminum pan. The samples were rapidly cooled to $-120^{\circ} \mathrm{C}$ and then heated to $200^{\circ} \mathrm{C}$ at a rate of $10^{\circ} \mathrm{C} / \mathrm{min}$.

Thermogravimetric analyses (TGA) were performed on a Seiko Instruments TG/DTA6200 at a heating rate of $10^{\circ} \mathrm{C} / \mathrm{min}$ from $30^{\circ} \mathrm{C}$ to $500^{\circ} \mathrm{C}$ under an $\mathrm{N}_{2}$ atmosphere.

\subsubsection{Surface Analysis}

Atomic force microscopy (AFM) analyses were performed on dried sheets at room temperature $\left(23^{\circ} \mathrm{C} \pm 2^{\circ} \mathrm{C}\right)$ in air using an Olympus NV2000. Most of the images were obtained in tapping mode (ACAFM) with a silicon nitride cantilever (OMMCL-AC 240TS-C2, Olympus optical) using a spring constant of $15 \mathrm{~N} / \mathrm{m}$ and a resonating frequency of $20 \mathrm{KHz}$. The scanning rates were varied from 1 to $2 \mathrm{~Hz}$. All the images presented here were reproduced from images obtained from at least three points on each sample surface.

\section{Results and Discussion}

\subsection{NMR Spectroscopy}

Analyses by ${ }^{1} \mathrm{H}$ NMR and ${ }^{13} \mathrm{C}$ NMR spectroscopy revealed that the polymers obtained were undoubtedly PUEs containing sucrose and that these polymers were composed from a urethane segment and sucrose. The NMR analyses indicated that sucrose was attached to the main PU chain as a cross-linker. For example, ${ }^{1} \mathrm{H}$ NMR of PUE-PTMG-S1 (Figure 1); $\delta 8.54(\mathrm{CO}-\mathrm{NH}), 7.31$ and $7.08\left(-\mathrm{C}_{6} \mathrm{H}_{4}{ }^{-}\right), 5.10-4.27(\mathrm{CH}(\mathrm{OH})), 4.05$ and 3.27 $\left(\mathrm{O}-\mathrm{CH}_{2}\right), 3.78\left(-\mathrm{C}_{6} \mathrm{H}_{4}-\mathrm{CH}_{2}-\mathrm{C}_{6} \mathrm{H}_{4}-\right)$, and $1.49\left(-\mathrm{CH}_{2}-\mathrm{CH}_{2}-,-\mathrm{CH}(\mathrm{R})-\right)$ and ${ }^{13} \mathrm{C}$ NMR of PUE-PTMG-S1; $\delta 129$ $(\mathrm{C}=\mathrm{C}), 118(\mathrm{C}=\mathrm{C}), 70\left(\mathrm{O}-\mathrm{CH}_{2}\right)$, and $26\left(\mathrm{CH}_{2}\right)$.

\subsection{FTIR Spectroscopy}

The representative IR spectrum of PUE-PTMG-S1 is shown in Figure 2. The IR spectroscopy analysis of PUE-PTMG-S1 was used to check the end of polyaddition reaction. The absence of the characteristic NCO band at $2265 \mathrm{~cm}^{-1}$, appearance of $\mathrm{N}-\mathrm{H}$ stretching band at $3300 \mathrm{~cm}^{-1}, \mathrm{~N}-\mathrm{H}$ bending band and $\mathrm{C}-\mathrm{N}$ stretching band of amide II at $1530 \mathrm{~cm}^{-1}$, and $\mathrm{C}=\mathrm{O}$ stretching band at $1725 \mathrm{~cm}^{-1}$ confirmed the end of the polyaddition reaction and formation of PU linkages. The characteristic absorption bands at $2794-2940 \mathrm{~cm}^{-1}$ indicated that the $-\mathrm{CH}_{2^{-}}$ asymmetric stretching mode is available in the synthesized PUE-PTMG-S1. The band at $1647 \mathrm{~cm}^{-1}$ was attributed to the amide II stretching mode of PU. The band at $1093 \mathrm{~cm}^{-1}$ is due to the asymmetric stretching of C-O-C linkage.

\subsection{GPC}

The GPC of PUEs containing sucrose units is reported in Table 3. For example, PUE-PTMG-S1; Mw 340,000; $\mathrm{Mw} / \mathrm{Mn} 1.3$.

\subsection{Chemical Properties}

The solvent resistances of the sucrose-containing PUEs were tested by immersing each PUE sheet in various 


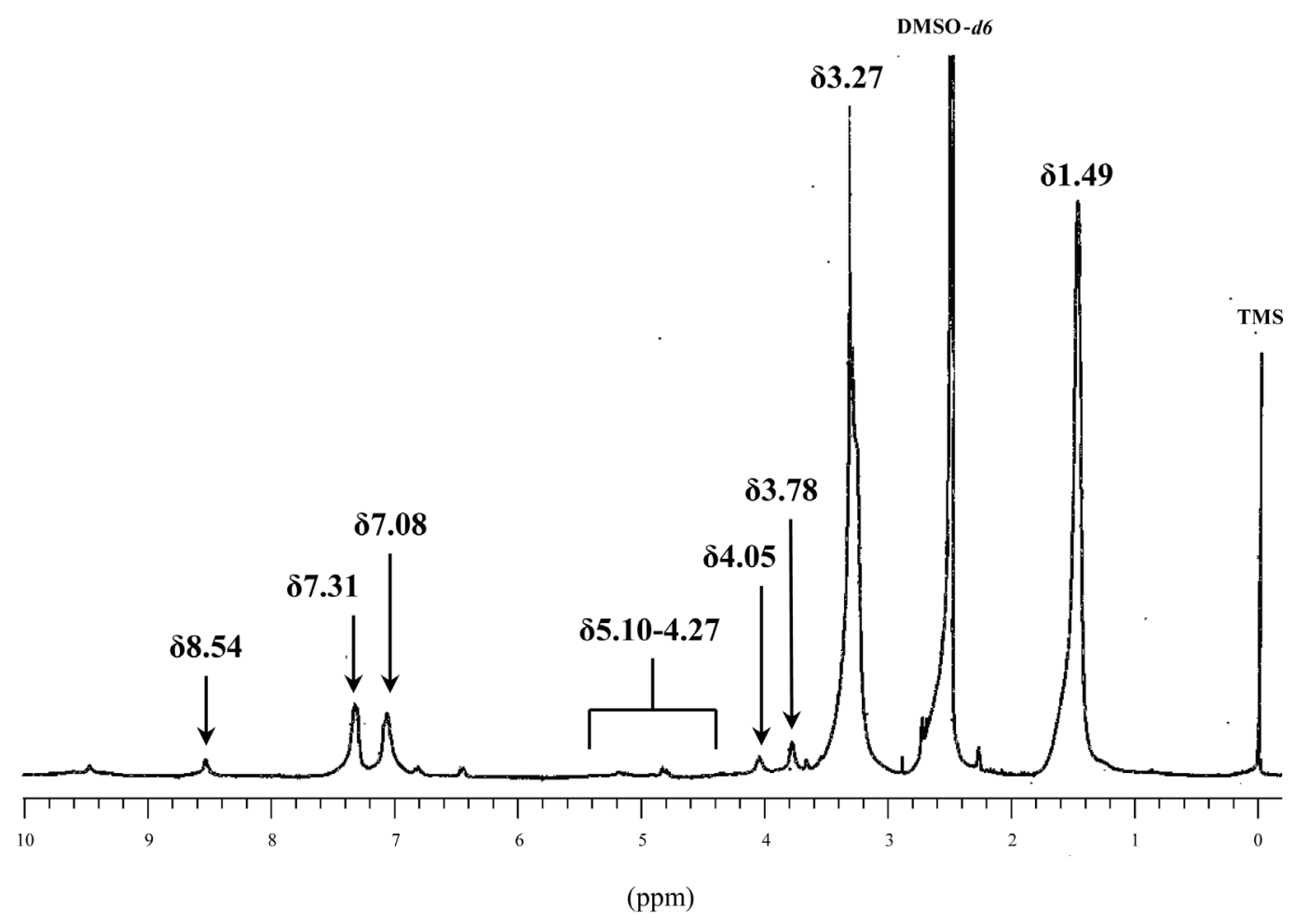

Figure 1. ${ }^{1} \mathrm{H}$ NMR spectrum of PUE-PTMG-S1.

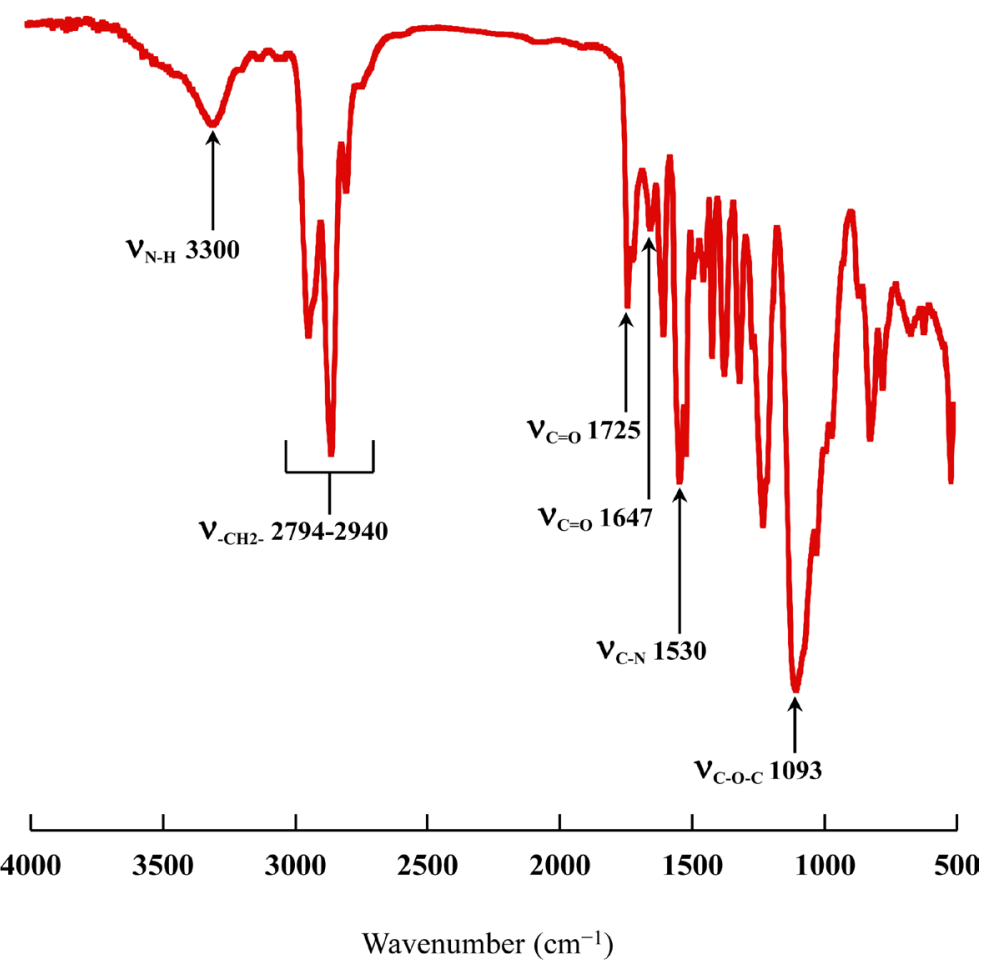

Figure 2. FTIR-ATR spectrum of PUE-PTMG-S1.

solvents including hexane, benzene, toluene, acetone, THF, DMF, and DMSO. The results are presented in Table 2. All the sucrose-containing PUEs were resistant to hexane and acetone and swelled in benzene, THF, DMF, 
Table 2. Solubilities of polyurethane elastomers containing sucrose.

\begin{tabular}{ccccccccc}
\hline Sample, & Benzene $^{\mathrm{c}}$ & Hexane $^{\mathrm{c}}$ & $\mathrm{THF}^{\mathrm{c}}$ & \multicolumn{2}{c}{ DMF $^{\mathrm{d}}$} & \multicolumn{2}{c}{$\mathrm{DMSO}^{\mathrm{d}}$} \\
\hline PUE-Polyol-S1 & & & $23^{\circ} \mathrm{C}$ & $100^{\circ} \mathrm{C}$ & $23^{\circ} \mathrm{C}$ & $100^{\circ} \mathrm{C}$ \\
PUE-Polyol-S2 & $\square$ & $\times$ & $\times$ & $\square$ & $\Delta$ & $\square$ & $\Delta$ \\
PUE-Polyol-S3 & $\square$ & $\times$ & $\times$ & $\square$ & $\Delta$ & $\square$ & $\Delta$ \\
PUE-Polyol-S4 & $\square$ & $\times$ & $\times$ & $\square$ & $\Delta$ & $\square$ & $\Delta$ \\
PUE-Polyol-S5 & $\square$ & $\times$ & $\times$ & $\square$ & $\Delta$ & $\square$ & $\Delta$ \\
PUE-Polyol & $\square$ & $\times$ & $\times$ & $\square$ & $\Delta$ & $\square$ & $\Delta$ \\
\hline
\end{tabular}

○: completely dissolved, $\Delta$ : slightly dissolved, $\square$ : swelled, $\times$ : undissolved. ${ }^{\text {a} P o l y o l: ~ p o l y o x y t e t r a m e t h y l e n e ~ g l y c o l ~(m o l e c u l a r ~ w e i g h t ~}=2000$; PTMG 2000), polycaprolactone diol (molecular weight $=2000$; PCL2000), and polycarbonate diol (molecular weight $=2000$; PCD2000). ${ }^{b}$ Measurement conditions: benzene, hexane, acetone, THF, DMF, or DMSO as the solvent at room temperature $\left(23^{\circ} \mathrm{C} \pm 2^{\circ} \mathrm{C}\right)$ or $100^{\circ} \mathrm{C}$ (for DMF and DMSO) for 24 h. ${ }^{\circ}$ Room temperature $\left(23^{\circ} \mathrm{C} \pm 2^{\circ} \mathrm{C}\right)$. ${ }^{d}$ Room temperature $\left(23^{\circ} \mathrm{C} \pm 2^{\circ} \mathrm{C}\right)$ and $100^{\circ} \mathrm{C}$.

and DMSO at room temperature $\left(23^{\circ} \mathrm{C} \pm 2^{\circ} \mathrm{C}\right)$. Notably, the corresponding PUEs without sucrose dissolved completely in DMSO and DMF at $100^{\circ} \mathrm{C}$, whereas the sucrose-containing PUEs dissolved only slightly. In general, the sucrose-containing PUEs exhibited good solvent resistance. These results suggest that the sucrose-containing PUEs can form interpenetrating polymer networks [30].

\subsection{Mechanical Properties}

The tensile properties of the sucrose-containing PUEs are reported in Figure 3. The tensile strengths and elongation at breaking points for PUE-(PTMG/PCL/PCD)-S1 and S2 were greater than those for PUE-(PTMG/ PCL/PCD) except for the elongation at the breaking point of PUE-PTMG-S1. However, for PUE-(PTMG/PCL/ PCD)-S2-S5, the tensile strengths and elongation at breaking points for the polymers decreased with the sucrose contents. These results suggested that the effect of sucrose on the higher-order conformation expanded to the overall structure as the sucrose contents increased. Note that the stiffness of the sucrose-containing PUEs increased as the formation of the PUEs progressed and the sucrose contents increased. As a result, PUE-(PTMG/ PCL/PCD)-S1 exhibited the best elastomeric behavior.

The results of hardness, swelling tests, DSC, and TGA are presented in Table 3. The hardness of the sucrosecontaining PUEs increased with the sucrose contents, whereas their swelling rates decreased. These results corresponded with those of the tensile tests and suggested that the network chain densities in the sucrose-containing PUEs increased with the sucrose contents.

\subsection{Thermal Properties}

DSC analyses of the sucrose-containing PUEs were performed over $-120^{\circ} \mathrm{C}$ to $200^{\circ} \mathrm{C}$ under an $\mathrm{Ar}$ atmosphere. From the data in Table 3, one main transition occurred for the sucrose-containing PUEs. The values for the glass transition temperatures ( $\mathrm{Tg}$, determined as the peak temperature in the E' curves) of the corresponding PUEs without sucrose content were $-67.0^{\circ} \mathrm{C},-45.0^{\circ} \mathrm{C}$, and $-26.4^{\circ} \mathrm{C}$ for PUE-PTMG, PUE-PCL, and PUE-PCD, respectively. Notably, as the sucrose contents in the sucrose-containing PUEs increased, the $\mathrm{Tg}$ values increased. This peak corresponded to the breaking of the glycosidic bond in the sucrose segment of the sucrose-containing PUEs.

The thermal stabilities of the sucrose-containing PUEs were examined via TGA under an $\mathrm{N}_{2}$ atmosphere. Table 3 shows that for the three types of PUEs with different polyols, the $10 \mathrm{wt} \%$ weight loss temperature $\left(T_{10}\right)$ decreased as the sucrose contents in the sucrose-containing PUEs increased. However, the $T_{10}$ values for sucrose-containing PUEs were higher than those of PUE-(PTMG/PCL/PCD).

DMA measurements of the sucrose-containing PUEs were performed over $-100^{\circ} \mathrm{C}$ to $300^{\circ} \mathrm{C}$. Rubbery flat regions were not observed in PUE-(PTMG/PCL/PCD)-S3-S5 but in PUE-(PTMG/PCL/PCD)-S1 and S2 at approximately $50^{\circ} \mathrm{C}-180^{\circ} \mathrm{C}$. In addition, the rubbery flat regions for PUE-(PTMG/PCL/PCD)-S1 and S2 declined significantly in comparison with those observed for PUE-(PTMG/PCL/PCD). These results suggested that the 

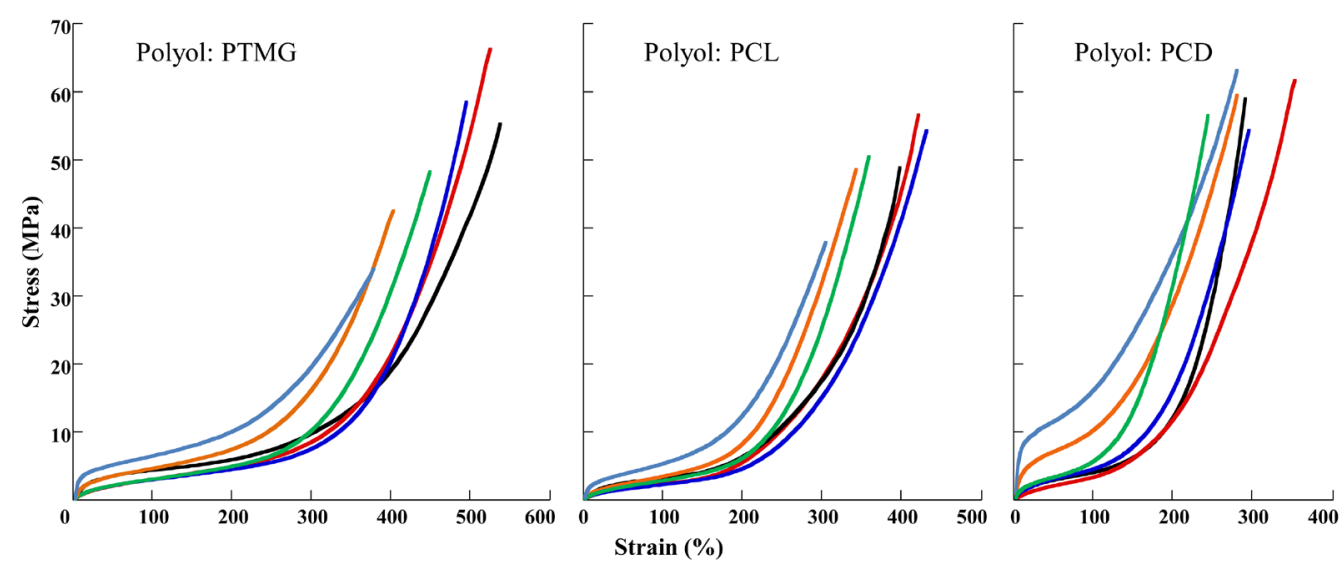

- PUE-Polyol ； - PUE-Polyol-S S $_{1}$

— PUE-Polyol-S S $_{2} ;$ PUE-

(a)

(b)

(c)

Figure 3. Tensile properties of polyurethane elastomers containing various concentrations of sucrose. PUEs were synthesized using (a) MDI, PTMG2000, and sucrose; (b) MDI, PCL2000, and sucrose; and (c) MDI, PCD2000, and sucrose. Sucrose content: black, 0\%; red, $1.4 \mathrm{wt} \%$; deep blue, $3.1 \mathrm{wt} \%$; green, $5.0 \mathrm{wt} \%$; orange, $7.6 \mathrm{wt} \%$; light blue, $10 \mathrm{wt} \%$.

Table 3. Physical properties of polyurethane elastomers containing sucrose.

\begin{tabular}{|c|c|c|c|c|c|c|}
\hline Sample & $\begin{array}{l}\text { Hardness }^{\mathrm{a}} \\
\text { (JIS A) }\end{array}$ & $\begin{array}{c}\text { Swelling rate } \\
(\%)\end{array}$ & $\begin{array}{l}\mathrm{Tg}^{\mathrm{C}} \\
\left({ }^{\circ} \mathrm{C}\right)\end{array}$ & $\begin{array}{l}\mathrm{T}_{10}{ }^{\mathrm{d}} \\
\left({ }^{\circ} \mathrm{C}\right)\end{array}$ & $\begin{array}{c}M \mathrm{w}^{\mathrm{e}} \\
\left(\times 10^{4}\right)\end{array}$ & $M \mathrm{w} / M \mathrm{n}^{\mathrm{e}}$ \\
\hline PUE-PTMG-S1 & 65 & 294 & -63.0 & 348 & 34 & 13 \\
\hline PUE-PTMG-S2 & 66 & 298 & -63.1 & 342 & 11 & 16 \\
\hline PUE-PTMG-S3 & 71 & 285 & -62.7 & 330 & 5.0 & 17 \\
\hline PUE-PTMG-S4 & 77 & 235 & -61.7 & 310 & 4.7 & 15 \\
\hline PUE-PTMG-S5 & 85 & 220 & -61.6 & 282 & 4.3 & 14 \\
\hline PUE-PTMG & 77 & 229 & -67.0 & 351 & 38 & 4.8 \\
\hline PUE-PCL-S1 & 62 & 234 & -48.8 & 350 & 21 & 19 \\
\hline PUE-PCL-S2 & 61 & 229 & -41.3 & 341 & 12 & 18 \\
\hline PUE-PCL-S3 & 65 & 214 & -41.3 & 327 & 5.4 & 18 \\
\hline PUE-PCL-S4 & 67 & 213 & -39.6 & 314 & 4.1 & 17 \\
\hline PUE-PCL-S5 & 86 & 199 & -38.8 & 298 & 2.1 & 15 \\
\hline PUE-PCL & 67 & 204 & -45.0 & 338 & 16 & 3.5 \\
\hline PUE-PCD-S1 & 70 & 251 & -30.4 & 336 & 8.4 & 17 \\
\hline PUE-PCD-S2 & 73 & 247 & -27.9 & 331 & 4.8 & 18 \\
\hline PUE-PCD-S3 & 78 & 240 & -26.1 & 323 & 3.8 & 14 \\
\hline PUE-PCD-S4 & 89 & 230 & -25.5 & 311 & 3.7 & 12 \\
\hline PUE-PCD-S5 & 97 & 222 & -24.4 & 296 & 2.6 & 13 \\
\hline PUE-PCD & 79 & 195 & -26.4 & 313 & 21 & 3.6 \\
\hline
\end{tabular}

${ }^{\mathrm{a}}$ Measurement conditions: JIS A type, total thickness $=6 \mathrm{~mm}$, room temperature $\left(23^{\circ} \mathrm{C} \pm 2^{\circ} \mathrm{C}\right)$. ${ }^{\mathrm{b}}$ Measurement conditions: benzene solvent at room temperature $\left(23^{\circ} \mathrm{C} \pm 2^{\circ} \mathrm{C}\right)$ for $24 \mathrm{~h}$. ${ }^{\circ}$ Differential scanning calorimetry was performed at a heating rate of $10^{\circ} \mathrm{C} / \mathrm{min}$ from $-120^{\circ} \mathrm{C}$ to $200^{\circ} \mathrm{C}$ under an $\mathrm{Ar}$ atmosphere. ${ }^{\mathrm{d}}$ Thermogravimetric analysis was performed at a heating rate of $10^{\circ} \mathrm{C} / \mathrm{min}$ from $30^{\circ} \mathrm{C}$ to $500^{\circ} \mathrm{C}$ under an $\mathrm{N}_{2}$ atmosphere. ${ }^{\mathrm{e}} \mathrm{Measurements}$ conditions: solvent $=N, N$-dimethylformamide, sample $=0.1 \mathrm{wt} \%(N, N$-dimethylformamide/dimethyl sulfoxide $=1 / 1 \mathrm{solution})$, flow rate $500 \mu \mathrm{L} / \mathrm{min}$, measurement temperature $=40^{\circ} \mathrm{C}$. 
molecular chain lengths between cross-linked polymers were reduced following the addition of a small amount of sucrose. Regarding PUE-(PTMG/PCL/PCD)-S3-S5, the characteristic S-shaped curves were not observed, and the E' values increased. These results suggested that the sucrose-containing PUEs calcified as sucrose contents increased. The $\tan \delta$ values also shifted to the high-temperature area as the sucrose contents and values of the peak top simultaneously increased. These results agreed with the DSC results. Furthermore, two different peaks were present as small broad peaks in the curves of PUE-(PTMG/PCL/PCD)-S1-S3 in the DMA curves for PUE-(PTMG/PCL/PCD)-S4 and S5. The peak in the low-temperature area is attributed to the sucrose segment, and the peak on the high-temperature area may be attributed to the PU chains.

\subsection{Surface Properties}

AFM images of the sucrose-containing PUEs (Figure 4) revealed that all the investigated sample sheets were continuous organic layers with a roughness less than the sheet thickness. The incorporation of the sucrose into the surface structures was visible. In addition, the surfaces of the sucrose-containing PUEs were compared with those of the corresponding PUEs without sucrose. The surfaces of the sheets of the sucrose-containing PUEs became flatter as the sucrose content was increased.

\section{Conclusions}

In summary, we achieved the synthesis of PUs with retained elastic properties using the one-shot method. The use of sucrose as a cross-linker was essential to obtain the desired PUEs. This study enabled the synthesis of PUEs introduced with sucrose units, which act as a cross-linker in the main chain.

The sheets of PU containing sucrose are transparent. The experiment results showed that the hardness of the polymer increases with the sucrose content of PUE. On the contrary, the sheet becomes slightly brittle, and hence, its flexibility is unsatisfactory. The increase in the hardness was due to the sucrose inter-chain interact-

\section{PUE-PTMG}

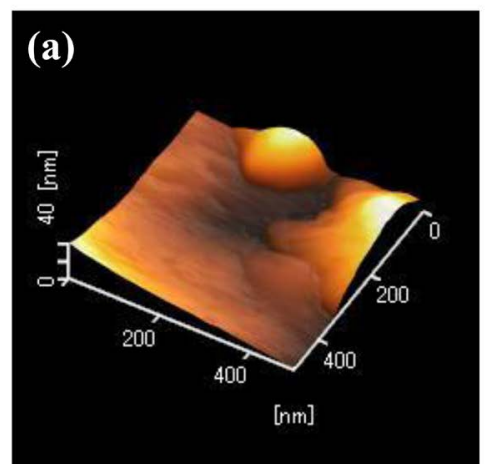

PUE-PTMG-S5

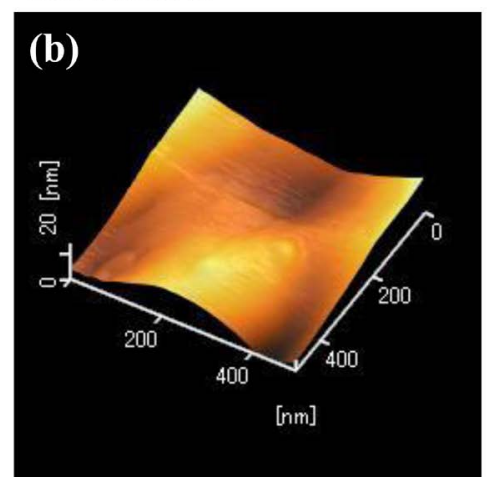

Figure 4. AFM images of polyurethane elastomer without (PUE-PTMG) and with sucrose (PUE-PTMG-S5). (a) and (b) $500 \times 500 \mathrm{~nm}$; (A) and (B) $1000 \times$ $1000 \mathrm{~nm}$.
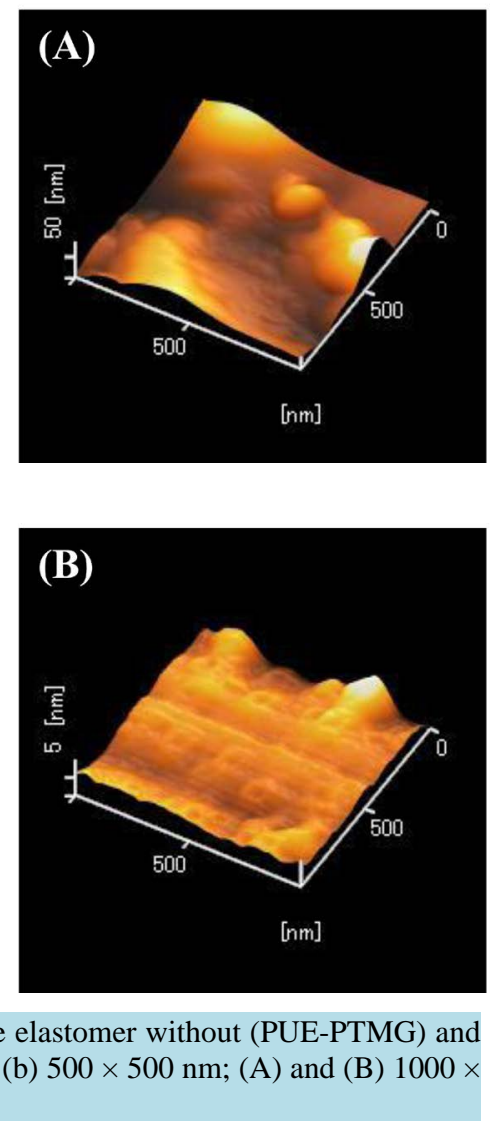
tions because of the hydrogen bonds with urethane moieties. The stability and chemical resistance were strengthened in the high sucrose content. Regarding its applications, the sucrose-containing PUE is recommended for use in commercial and industrial polymers. This study needs to be further extended by studying the biodegradable properties of the sucrose-containing PUE.

\section{References}

[1] Szycher, M. (1999) Szycher’s Handbook of Polyurethanes, 1.1-9. CRC Press, Boca Raton.

[2] Wirtz, H. and Schulte, K. (1973) Processing of Polyurethane Foam Systems. Kunststoffe, 63, 726-730.

[3] Avar, G., Meier, W.U., Casselmann, H. and Achten, D. (2012) Polymer Science: A Comprehensive Reference. Polymer Science: A Comprehensive Reference, 10, 411-441.

[4] Kuehn, A.F. (1986) Polyurethane-A Promising Prospect in Roll Coverings. PIMA, 68, 27-28.

[5] Bez, W. and Quack, G. (1983) Polyurethane and Latex Foam Carpet Backing Today. Cellular Polymers, 2, 31-53.

[6] Gagro, D. (2010) Polyurethanes Overview of the PUR Market. European Coatings Journal, 10, 9-11.

[7] Hare, C.H. (2000) A Review of Polyurethanes: Formulation Variables and their Effects on Performance. Journal of Protective Coatings and Linings, 17, 34-44.

[8] Walter, R.F. (1969) Sucrose-Ethylene Diamine Polyols and Process for Preparing Same. US Patent 3640997.

[9] Neil, H.N. (1978) Sucrose Based Polyether Polyols. US Patent 4230824.

[10] Hatakeyama, H., Hirose, S. and Hatakeyama, T. (1995) Biodegradable Polyurethanes from Plant Components. Journal of Macromolecular Science, Pure and Applied Chemistry, A32, 743-750. http://dx.doi.org/10.1080/10601329508010285

[11] Asano, Y. and Hatakeyama, H. (2003) Rigid Type Polyurethane Foams Containing Saccharide and Lignin Structures in the Molecular Chain. Memoirs of Fukui University of Technology, 33, 275-282.

[12] Hatakeyama, H. and Hatakeyama, T. (2005) Environmentally Compatible Hybrid Type Polyurethane Foams Containing Saccharide and Lignin Components. Macromolecular Symposia, 224, 219-226. http://dx.doi.org/10.1002/masy.200550619

[13] Chen, Q., Li, R., Sun, K., Li, J. and Liu, C. (2011) Preparation of Bio-Degradable Polyurethane Foams from Liquefied Wheat Straw. Advanced Materials Research, 217, 1239-1244. http://dx.doi.org/10.4028/www.scientific.net/amr.217-218.1239

[14] Wang, G. and Zhou, A. (2011) Soy Protein Based Biodegradable Flexible Polyurethane Foam. Advanced Materials Research, 152, 1862-1865.

[15] Garcon, R., Clerk, C., Gesson, J.-P., Bordado, J., Nunes, T., Caroco, S., Gomes, P.T., Minas da Piedade, M.E. and Rauter, A.P. (2001) Synthesis of Novel Polyurethanes from Sugars and 1,6-Hexamethylene Diisocyanate. Carbohydrate Polymers, 45, 123-127. http://dx.doi.org/10.1016/S0144-8617(00)00323-4

[16] Lim, H., Kim, E.Y. and Kim, B.K. (2010) Polyurethane Foams Blown with Various Types of Environmentally Friendly Blowing Agents. Plastics, Rubber and Composites, 39, 364-369. http://dx.doi.org/10.1179/174328910X12691245469835

[17] Ionescu, M., Mihalache, I., Zugravu, V. and Mihai, S. (1994) Inherently Flame Retardant Rigid Polyurethane Foams Based on New Triazinic Polyether Polyols. Cellular Polymers, 13, 57-68.

[18] Guo, A., Demydov, D., Zhang, W., Zoran, W. and Petrovie, S. (2002) Polyols and Polyurethanes from Hydroformylation of Soybean Oil. Journal of Polymers and the Environment, 10, 49-52. http://dx.doi.org/10.1023/A:1021022123733

[19] Dhanjay, J. and Alain, D. (1997) Sucrose-Based Polymers: Polyurethanes with Sucrose in the Main Chain. European Polymer Journal, 33, 1577-1582. http://dx.doi.org/10.1016/S0014-3057(97)00056-6

[20] Foote, J.F., Le, B.L.R. and Marco, W. (1966) US Patent 3265641.

[21] Mir, G., Sadeghi, M., Shamsi, R. and Sayaf, M. (2011) From Aminolysis Product of PET Waste to Novel Biodegradable Polyuretuhanes. Journal of Polymers and the Environment, 19, 522-534. http://dx.doi.org/10.1007/s10924-011-0283-7

[22] Kim, S.H., Lim, H. and Kim, B.K. (2008) Effects of Initiator Type in Rigid Polyurethane Foams. Polmer Engineering and Science, 48, 1518-1523. http://dx.doi.org/10.1002/pen.21122

[23] Kim, B.K. and Paik, S.H. (1999) UV-Curable Poly(ethylene glycol)-Based Polyurethane Acrylate Hydrogel. Journal of Polymer Science Part A, 37, 2703-2709. http://dx.doi.org/10.1002/(SICI)1099-0518(19990801)37:15<2703::AID-POLA3>3.0.CO;2-A 
[24] Laijiu, Z., Bing, D. and Zeshou, H. (2013) Treatment of Wool Scouring Wastewater by Immobilized Chitosan BioMembrane. Journal of Engineered Fibers and Fabrics, 8, 1-5.

[25] Pan, X. and Webster, D.C. (2012) New Biobased High Functionality Polyols and Their Use in Polyurethane Coatings. ChemSusChem, 5, 419-429. http://dx.doi.org/10.1002/cssc.201100415

[26] Deka, H. and Karak, N. (2009) Bio-Based Hyperbranched Polyurethanes for Surface Coating Applications. Progress in Organic Coatings, 66, 192-198. http://dx.doi.org/10.1016/j.porgcoat.2009.07.005

[27] Hasirci, N. and Aksoy, E.A. (2007) Synthesis and Modifications of Polyurethanes for Biomedical Purposes. High Performance Polymer, 19, 621-637. http://dx.doi.org/10.1177/0954008307081203

[28] Yeganeh, H., Jamshidi, H. and Jamshidi, S. (2007) Synthesis and Properties of Novel Biodegradable Poly( $\varepsilon$-caprolactone)/ Poly(ethylene glycol)-Based Polyurethane Elastomers. Polymer International, 56, 41-49. http://dx.doi.org/10.1002/pi.2107

[29] Szycher, M. (1999) Szycher’s Handbook of Polyurethanes, 3.4-9. CRC Press, Boca Raton.

[30] Daniel, K., Sperling, L.H. and Utracki, L.A. (1991) Interpenetrating Polymer Networks, ACS. 